\title{
A INFÂNCIA E AS BRINCADEIRAS NO ENSINO FUNDAMENTAL DE NOVE ANOS: Questões para a formação e atuação de professores
}

\author{
CHILDHOOD AND PLAY IN FUNDAMENTAL EDUCATION OF NINE YEARS: \\ Questions for the training and performance of teachers
}

Sonara Maria Lopes de Oliveira ${ }^{1}$

Jaqueline Delgado Paschoal ${ }^{2}$

\section{http://dx.doi.org/10.52641/cadcaj.v6i4.530}

RESUMO: Este estudo tem como objetivo principal, demonstrar a relevância das brincadeiras para a aprendizagem e desenvolvimento da criança, bem como a necessária utilização dessas atividades como ferramenta de trabalho dos professores. Justifica-se a importância da temática, pois acredita-se que o perfil da criança que ingressa nos anos iniciais se caracteriza pela imaginação, pela curiosidade, pelo movimento e pelo desejo de aprender aliados à sua forma privilegiada de conhecer o mundo por meio do brincar. Dessa forma, o desconhecimento das especificidades da infância e do trabalho pedagógico nessa etapa da Educação Básica, pode levar às práticas equivocadas de desvalorização das atividades lúdicas em detrimento de exercícios que privilegiam a memorização das letras e dos números. De caráter bibliográfico, a pesquisa se pautou na perspectiva crítico-dialética, visto que essa concepção defende que o conhecimento se processa na e pela práxis. Os resultados evidenciam que muitos são os desafios para a efetiva absorção das brincadeiras no cotidiano da sala de aula. Daí a importância da formação inicial e continuada dos professores, para a melhoria das práticas lúdicas desenvolvidas com as crianças no contexto escolar.

Palavras-chave: Infância; brincadeiras; aprendizagem; Anos Iniciais.

ABSTRACT: This study has as main objective, to demonstrate the relevance of the games for the child's learning and development, as well as the necessary use of these activities as a work tool of the teachers. The importance of the theme is justified, as it is believed that the profile of the child who enters the early years is characterized by imagination, curiosity, movement and the desire to learn allied to his privileged way of knowing the world through playing. Thus, the lack of knowledge about the specificities of childhood and pedagogical work in this stage of Basic Education, can lead to the wrong practices of devaluing playful activities to the detriment of exercises that privilege the memorization of letters and numbers. With a bibliographic character, the research was based on the critical-dialectic perspective, since this conception defends that knowledge is processed in and by praxis. The results show that there are many challenges for the effective absorption of games in the classroom. Hence the importance of initial and continuing training for teachers, for the improvement of playful practices developed with children in the school context.

Keywords: Childhood; games; learning; Early Years.

\footnotetext{
${ }^{1}$ Mestre em Educação pela Universidade Estadual de Londrina. Coordenadora pedagógica da Educação Infantil e Anos Iniciais do Ensino Fundamental do Colégio Mãe de Deus.

2Pós-Doutora em Educação pela Universidade Júlio de Mesquita Filho/UNESP/Assis. Professora Associada no Departamento de Educação da Universidade Estadual de Londrina. Docente do Curso de Pedagogia e do Programa de Pós-Graduação-Mestrado e Doutorado em Educação da UEL.
} 


\section{INTRODUÇÃO}

Analisar a infância é contemplar o começo da vida, que é permeado por risos e choros, brincadeiras e fantasias, surpresas e descobertas, tentativas de compreender e conquistar esse mundo que se apresenta aos olhos e sentidos. Pensar a infância pode ser rememorar o próprio passado, quando fizemos nossas primeiras experiências, agradáveis, entediantes, desconfortáveis e emocionantes; ao mesmo tempo, porém, pode ser inquietar-se diante das diferenças que percebemos nos modos e nas oportunidades de viver a infância.

A infância é uma fase singular da vida do ser humano que não pode, de forma alguma, ser suprimida, roubada ou reduzida, seja por causa da pobreza, da ausência de cuidados, do descaso ou da antecipação de responsabilidades que não lhe pertencem. Na prática, "trata-se de deixar de ser infans - aquele que não fala, para a capacidade de falar" (KRAMER, 2000, p.11), no sentido de não permitir que o silêncio sobre a infância e seus direitos desencadeie um retrocesso a tempos antigos. Para Kramer (2000, p. 12) "valorizar a infância e lutar pela sua não destruição significa, portanto, participar de uma luta que temos perdido historicamente, que visa defender e garantir à humanidade, a capacidade de rir e brincar".

Do ponto de vista legal, a Constituição Federal (1988) assegurou à criança prioridade de direitos no que se refere à saúde, alimentação, educação, lazer, cultura, respeito e liberdade, bem como, proteção contra a negligência, a discriminação, a exploração, a violência, a crueldade e a opressão. Assim, reconheceu a criança como sujeito de direitos, inclusive o direito à educação desde o nascimento.

Em 1990, o Estatuto da Criança e do Adolescente- Lei 8.069/90 (BRASIL,1990) estabeleceu que criança é a pessoa de até doze anos de idade incompletos, e confirmou os direitos preconizados pela carta constituinte. Assim, determinou que os direitos sejam assegurados a todas as crianças, de modo que não haja qualquer tipo de discriminação no que se refere "ao nascimento, situação familiar, idade, sexo, raça, etnia ou cor, religião ou crença, deficiência, condição pessoal de desenvolvimento e aprendizagem, condição econômica, ambiente social, região e local de moradia" (BRASIL, 1990). Em seu Artigo $3^{\circ}$, reiterou que "a criança e o adolescente gozam de todos os direitos fundamentais inerentes à pessoa humana" e lhes assegura “o desenvolvimento físico, mental, moral, espiritual e social, em condições de liberdade e de dignidade" (BRASIL, 1990).

O século XX teve, portanto, seu início marcado pela consciência da importância da infância como fase de grandes transformações na vida do indivíduo, assim como, pela conquista 
dos direitos da criança e pela garantia de proteção por parte da família, da comunidade, da sociedade em geral e do poder público. Desde muito pequena, a criança é inserida em um mundo social, e é a partir de suas interações e das relações sociais que vivencia que ela "constrói sua identidade pessoal e coletiva, brinca, imagina, fantasia, deseja, aprende, observa, experimenta, narra, questiona e constrói sentidos sobre a natureza e a sociedade, produzindo cultura" (BRASIL, 2010, p 12).

Assim, a partir da concepção de criança como sujeito histórico e de direitos, a educação escolar torna-se lugar privilegiado de promoção da infância e de seus direitos e peculiaridades, capaz de contribuir para o seu desenvolvimento integral, de modo a formar indivíduos que sejam capazes de transformar a sociedade. $\mathrm{Na}$ escola, a criança "se desenvolve nas interações, relações e práticas cotidianas a ela disponibilizadas e por ela estabelecidas com adultos e crianças de diferentes idades nos grupos e contextos culturais nos quais se insere” (BRASIL, 2013, p.86).

Nessa direção, "é preciso aperfeiçoar o conteúdo e os métodos educativos para assegurar em cada idade da criança as vivências necessárias para o desenvolvimento da personalidade e da inteligência em formação já na infância" (MELLO, 2007, p.91). Isso porque, conforme Mello (2007), as formações psicológicas desencadeadas nos primeiros anos de vida são importantes para o desenvolvimento do sujeito durante toda a vida, e as qualidades emocionais e intelectuais não concebidas adequadamente na infância podem redundar em problemas posteriores, na vida adulta.

É importante ressaltar que as experiências vivenciadas pelas crianças no contexto escolar, sobretudo àquelas que envolvem as interações, o diálogo, o aspecto lúdico, a corporeidade, o movimento e as expressões, contribuem de maneira significativa para a sua aprendizagem e desenvolvimento. Por isso, Kramer (2006, p. 810-811), acredita que “o planejamento e o acompanhamento pelos adultos devem levar em conta a singularidade das ações infantis e o direito à brincadeira e à produção cultural”. Destaca-se o papel do professor e a importância de seu olhar atento e respeitoso à criança e às suas necessidades de modo que a mesma encontre um ambiente acolhedor no qual experimente segurança e possa se desenvolver de maneira plena.

Nesse sentido como problema de pesquisa, questionou-se: "em que medida as brincadeiras contribuem para a aprendizagem das crianças no contexto do Anos Iniciais do ensino fundamental de nove anos?”. O objetivo geral foi demonstrar a relevância das brincadeiras para o aprendizado e desenvolvimento da criança, bem como a necessária utilização das atividades lúdicas como ferramenta de trabalho dos professores. Como objetivos específicos a intenção foi analisar a implantação do ensino fundamental de nove anos no Brasil a partir das recomendações legais; tecer considerações sobre o perfil da criança de seis anos de idade e 
entrada no primeiro ano do ensino de nove, além de apontar a relevância das brincadeiras na infância. De caráter bibliográfico, esse estudo se pautou na perspectiva crítico-dialética, pois como Frigotto (1994, p. 81), acredita-se que "no processo dialético de conhecimento da realidade", o que importa não é a crítica pela crítica, "mas a relação entre a crítica e o conhecimento crítico, para uma prática que altere e transforme a realidade no plano do conhecimento e no plano histórico-social”. Segundo o autor, essa concepção reconhece que o

conhecimento "efetivamente se dá na e pela práxis" (FRIGOTTO, 1994, p. 81).

Nesse contexto, são de fundamental importância os processos formativos dos professores, de modo que estes possam compreender as especificidades do trabalho pedagógico sem perder de vista as brincadeiras, a curiosidade, a magia, o encantamento e as diferentes linguagens das crianças. Isso porque defende-se, nesse trabalho, uma infância de risos, de curiosidade e descobertas, de interações, movimentos, encantos, afetos, plena de possibilidades de aprendizagem, desenvolvimento e conhecimento.

Para uma melhor organização da discussão, o estudo divide-se em duas seções, sendo que, a primeira apresentada a implementação do ensino de nove anos no Brasil a partir das recomendações legais e os desdobramentos no trabalho pedagógico com crianças a partir dos seis anos de idade. A segunda seção, discute o papel das brincadeiras na infância e o seu valor na aprendizagem e desenvolvimento infantil. Como contribuição, esta pesquisa pretende reiterar a necessária incorporação das brincadeiras como ferramenta de trabalho dos professores e a melhoria das práticas no contexto escolar por meio de uma educação de qualidade.

\section{A implantação do Ensino Fundamental de nove anos e as especificidades do trabalho docente}

Ao estabelecer o Ensino Fundamental de Nove Anos com início aos seis anos de idade, a educação, no Brasil, equiparou-se à ofertada por grande parte dos países desenvolvidos do ocidente, bem como da América Latina, no que se refere à obrigatoriedade, segundo as Diretrizes Curriculares Nacionais para a Educação Básica (2013). O documento relata que, na maioria desses países, verifica-se também a obrigatoriedade de matrícula para crianças no último ano da pré-escola, portanto, pode-se deduzir, desta afirmação, a indicação dos passos seguintes da legislatura nacional relativos ao ensino compulsório no país.

Desse modo, seguindo uma tendência universal, no ano de 2005, a Lei no $11.114 / 2005$ alterou o artigo $6^{\circ}$ da LDB (1996) e determinou que "é dever dos pais ou responsáveis efetuar a matrícula dos menores, a partir dos seis anos de idade, no Ensino Fundamental” (BRASIL, 2005). 
$\mathrm{Na}$ sequência, a Lei $\mathrm{n}^{\circ}$ 11.274/2006 alterou o artigo $32^{\circ}$ da LDB (1996) e instaurou o Ensino Fundamental de Nove Anos, determinando "o ensino fundamental obrigatório, com duração de 9 (nove) anos, gratuito na escola pública, iniciando-se aos 6 (seis) anos de idade” (BRASIL, 2006).

Entretanto, com o intuito de evitar modificações abruptas e prejuízos pedagógicos às crianças, foi concedido prazo até 2010 para que as alterações fossem realizadas em todos os estabelecimentos de ensino dos diversos estados e municípios. De acordo com um documento, intitulado Orientações Gerais para o Ensino Fundamental de Nove Anos, publicado pelo Ministério da Educação e Cultura no ano de 2004, o objetivo da ampliação da escolaridade obrigatória foi "assegurar a todas as crianças um tempo mais longo de convívio escolar, maiores oportunidades de aprender e, com isso, uma aprendizagem mais ampla” (BRASIL, 2004, p.17). Sobre essa questão, as Diretrizes Curriculares Nacionais Gerais da Educação Básica (2013), esclarecem:

O acesso ao Ensino Fundamental aos 6 (seis) anos permite que todas as crianças brasileiras possam usufruir do direito à educação, beneficiandose de um ambiente educativo mais voltado à alfabetização e ao letramento, à aquisição de conhecimentos de outras áreas e ao desenvolvimento de diversas formas de expressão, ambiente a que já estavam expostas as crianças dos segmentos de rendas média e alta e que pode aumentar a probabilidade de seu sucesso no processo de escolarização (BRASIL, 2013, p.109).

No que se refere à busca pela igualdade social, Saveli e Tenreiro (2011) consideram que a antecipação da entrada da criança de seis anos no Ensino Fundamental é uma política pública que favorece a equidade. Avaliam, ainda, que a determinação legal da obrigatoriedade de matrícula aos seis anos de idade é medida essencial na busca pelo combate à desigualdade social do país, pois representa um avanço importante quando oportuniza a inserção das crianças das camadas populares nos sistemas educacionais. Saveli e Tenreiro (2011) salientam, porém, que é essencial pensar, além do acesso, na garantia de permanência e na qualidade da oferta de educação a essas crianças.

A Constituição Federal (1988) estabelece, em seu artigo 212, \ $3^{\circ}$, que a destinação de "recursos públicos assegurará prioridade ao atendimento das necessidades do ensino obrigatório, no que se refere a universalização, garantia de padrão de qualidade e equidade, nos termos do plano nacional de educação" (BRASIL, 1988). Desse modo, pode-se considerar que a lei da obrigatoriedade do acesso ao Ensino Fundamental inclui as crianças de seis anos no rol de prioridades das políticas públicas. Tal fato, a princípio, deveria garantir o acesso, a permanência e a qualidade da educação escolar a um número maior de crianças. 
Nesse aspecto, porém, Breda (2016) identifica a existência de controvérsias no que concerne aos objetivos da determinação legal, pois, na década de 1990, foi criado o FUNDEF, Fundo de Manutenção e Desenvolvimento do Ensino Fundamental e Valorização do Magistério, posteriormente substituído pelo Fundo de Manutenção e Desenvolvimento da Educação Básica e de Valorização dos Profissionais da Educação, o FUNDEB (BREDA, 2016).

Conforme a análise de Breda (2016), desde a década de 1990 houve maior motivação para a inserção da criança de seis anos no Ensino Fundamental devido ao fato de que o FUNDEF se destinava a essa etapa educacional. Segundo a autora os estados e municípios "recebem recursos de acordo com os alunos matriculados no Ensino Fundamental, o que exclui tanto a Educação Infantil, quanto o Ensino Médio, níveis que também compõem a Educação Básica" (BREDA, 2016, p.17). Desse modo, o aspecto financeiro destaca-se como importante incentivo para a aprovação da lei que obriga a matrícula no primeiro ano com seis anos de idade.

A problemática situa-se no fato de que as recentes reorganizações ocasionadas pela antecipação da matrícula da criança nos Anos Iniciais, sob a perspectiva do aporte financeiro, perderam de vista o objetivo de maiores oportunidades de aprender e de uma aprendizagem mais ampla, pois, segundo Breda (2016), muitas crianças de apenas seis anos de idade passaram a se sentar em carteiras escolares durante quatro horas para serem alfabetizadas, o que pode acarretar sérias consequências para sua aprendizagem e desenvolvimento. Tais argumentos denunciam falta de atenção para as especificidades da criança nessa faixa etária, questão relevante quando se discute o direito de todo cidadão a uma educação de qualidade.

A esse respeito, Arelaro (2005) ressalta que os motivos que levaram à antecipação do ingresso da criança de seis anos no Ensino Fundamental foi a utilização dos recursos do FUNDEF, já que a Educação Infantil não contava com o aporte desse recurso. Para a autora (ARELARO, 2005, p.1047), o atendimento às crianças matriculadas na Educação Infantil "passaria a ser realizado disfarçado de Ensino Fundamental, mas manter-se-iam, nesse $1^{\circ}$ ano de Ensino Fundamental antecipado, as premissas e as orientações da Educação Infantil”.

Na perspectiva de Arelaro (2005), as novas determinações legais propõem apenas uma transferência do último ano da Educação Infantil e a incorporação deste ao Ensino Fundamental, ignorando a complexidade dessa transição e as especificidades de cada uma das etapas. A autora destaca, ainda, que a promulgação da Lei no 11.114 /2005 resulta em um número significativo de crianças de seis anos incorporadas às escolas de Ensino Fundamental, sem que tais instituições estejam preparadas com equipamentos e materiais pedagógicos adequados para a idade.

Nessa mesma linha de pensamento, Gorni, Maieski e Machado (2012, p.14) destacam que um ponto nevrálgico dessa ampliação do Ensino Fundamental é que "a preocupação não está 
focalizada no trabalho pedagógico, na estrutura física, na formação docente, mas no aumento do número de alunos". Essas contradições levam as autoras a considerarem que "alunos matriculados no Ensino Fundamental valiam mais, pois revertiam em maior repasse de verbas e em créditos políticos decorrentes da ampliação do acesso à educação" (GORNI; MAIESKI; MACHADO, 2012, p.14), e que, por esse motivo, a educação passou a ser equiparada a uma espécie de comércio.

Dessa forma, a ampliação de oportunidades de aprendizagem para a criança sofreu prejuízos devido à implementação de novas determinações nas escolas, uma vez que "os professores foram surpreendidos com a ampliação, sentindo-se desorientados quanto aos conteúdos a serem trabalhados no primeiro ano", conforme afirmam Gorni, Maieski e Machado (2012, p.19). Tal fato ocorreu porque, em sua maioria, as escolas transferiram as crianças do último ano da Educação Infantil para espaços destinados ao Ensino Fundamental, sem adequações de currículos, espaços e materiais e sem a formação dos professores.

Ainda sob esse ângulo, Guilherme (2009, p.19) menciona a suspeita de uma política pública pautada no que ela denomina de "preocupação excessiva com verbas, dados estatísticos, e órgãos financiadores", em detrimento do suporte e de condições necessárias para a implantação, implementação e desenvolvimento de uma proposta. A ausência do cuidado e da atenção necessários às circunstâncias em que a lei foi efetivada pode incorrer na garantia do direito à educação, porém sem abarcar o quesito qualidade desse direito.

O fracasso escolar nos Anos Iniciais do Ensino Fundamental, indicados em estatísticas e/ou pela constatação de que muitas crianças encerram esse ciclo sem os conhecimentos básicos esperados para essa etapa, é um problema assinalado por Guilherme (2009). A autora destaca, entretanto, que a solução para tal questão não depende "do tempo de duração ou idade de inclusão no Ensino Fundamental", mas da tomada de consciência de que "temos problemas de ensino e aprendizagem; problemas de concepção do que é ser criança, do que é ensinar e como se aprende", e são esses problemas que se deve perseguir e solucionar (GUILHERME, 2009, p.21).

É nesse contexto que reside a importância da elaboração de políticas públicas que abarquem questões urgentes que se referem às possibilidades reais de efetivação da lei, pois, conforme Brandão (2009, p. 23), “o mais importante é que as instâncias governamentais e seus respectivos sistemas de ensino proporcionem condições concretas para que a qualidade da educação ofertada no Ensino Fundamental não sofra prejuízo algum”. Dentre as medidas, o autor destaca, "a elaboração de uma política de formação de professores específica para as séries iniciais, a reorganização do tempo escolar e a articulação efetiva da primeira série do Ensino Fundamental com a Educação Infantil” (BRANDÃO, 2009, p.24). 
Em se tratando da qualidade do atendimento, Brandão (2009) esclarece ainda que, no primeiro ano, considerando-se que as crianças têm seis anos de idade, não podem ser desenvolvidas as mesmas atividades destinadas à Educação Infantil, ao mesmo tempo em que esta nova configuração não pode constituir antecipação dos conteúdos desenvolvidos na antiga primeira série. Assim, é necessária a elaboração de currículo e projeto político pedagógico específicos para o Ensino Fundamental, que abranjam os nove anos de escolarização, incluindo as crianças de seis anos.

Com esse propósito, o currículo, nessa etapa da Educação Básica, necessita da "estruturação de um projeto educativo coerente, articulado e integrado, de acordo com os modos de ser e de se desenvolver das crianças e dos adolescentes nos diferentes contextos sociais" (BRASIL, 2013, p.117), pois a criança de seis anos deve ser respeitada em suas especificidades, que são caracterizadas pela afetividade, pelo aspecto lúdico, pela curiosidade, pela criatividade, pelo constante movimento do corpo e seu contínuo desenvolvimento.

Nesse sentido, o documento Orientações Gerais para o Ensino Fundamental de Nove Anos (2004) determina que a escola deve "reorganizar a sua estrutura, as formas de gestão, os ambientes, os espaços, os tempos, os materiais, os conteúdos, as metodologias, os objetivos, o planejamento e a avaliação" (BRASIL, 2004, p.22), de forma que a criança seja acolhida em um ambiente propício à aprendizagem. Conforme o referido documento, faz-se "necessário assegurar que a transição da Educação Infantil para o Ensino Fundamental ocorra da forma mais natural possível, não provocando nas crianças rupturas e impactos negativos no seu processo de escolarização" (BRASIL, 2004, p.22).

No intuito de construir um currículo coerente com as necessidades da criança de seis anos, Gorni, Maieski e Machado (2012) enfatizam a importância do reconhecimento da infância e de sua centralidade nesse processo.

Tendo em vista que nos primeiros anos do Ensino Fundamental a criança passa a descobrir de maneira gradativa o universo sistemático da aquisição do conhecimento disposto nas diversas disciplinas, é importante que este processo ocorra de maneira "fascinante", impulsionando-a a se sentir sempre mais uma investigadora do seu próprio aprendizado. Para tanto, o respeito à infância é um elemento que deve ser cuidadosamente considerado na seleção e na organização dos conteúdos de ensino. Além disso, é importante que estes sejam significativos e atraentes para o aluno. (GORNI; MAIESKI; MACHADO, 2012, p.16)

Assim, fica evidente, conforme Moreno e Paschoal (2009), que não é o ingresso antecipado na escola que garante a ampliação da aprendizagem, mas a qualidade do trabalho 
desenvolvido em sala de aula. Para as autoras, a falta de entendimento da proposta priva a criança de viver uma fase de suma importância na infância, pois se tem priorizado a exigência de organização escolar, que prevê acúmulo de conhecimentos e conteúdos, muitas vezes, desassociados da realidade e dos interesses dos alunos.

Nesse sentido, considera-se imprescindível que, na proposta para o primeiro ano do Ensino Fundamental, sejam previstas atividades que, conforme as Diretrizes Curriculares Nacionais (2013), garantam: mobilidade às crianças na sala de aula; a exploração das diversas linguagens artísticas; o acesso a materiais que possibilitem o desenvolvimento do raciocínio; e a manipulação e exploração das características desses materiais. Essa proposta também precisa garantir a gradativa sistematização dos conhecimentos escolares (BRASIL, 2013).

Com base nesse entendimento, as salas de aula dos primeiros anos tornam-se locais de interações, afetos, brincadeiras, fantasias e descobertas, ao mesmo tempo em que constitui, de forma progressiva, local de sistematização de todos os conhecimentos e, nesse contexto, destacase o processo de alfabetização. Preocupação substancial dos sistemas de ensino, de professores e de pais, a questão da alfabetização converteu-se em elemento essencial das discussões relativas ao primeiro ano, muitas vezes, em detrimento de outros fatores importantes.

Questionamentos e dúvidas sobre o momento em que o trabalho de alfabetização deveria ser iniciado e sobre o tempo e a forma como este deveria se desenvolver foram e ainda são frequentes entre os envolvidos no processo de ingresso da criança de seis anos no Ensino Fundamental. Isso ocorre porque a leitura e a escrita têm relevância primordial nessa etapa da educação da criança, e seu êxito ou fracasso é fator determinante para a vida escolar do indivíduo.

$\mathrm{Na}$ realidade, as crianças, desde muito cedo, manifestam interesse pela leitura e escrita, assim, é papel da escola estimular este interesse em situações significativas. Além disso, é necessário um trabalho sistemático, que enfatize tanto aspectos funcionais e textuais, quanto aspectos gráficos da linguagem escrita e do sistema alfabético de representação (BRASIL, 2004). Embora as Diretrizes Curriculares Nacionais (2013) orientem que a alfabetização e o letramento ocorram nos três anos iniciais do Ensino Fundamental, a Base Nacional Curricular Comum (2017) determina que "é nos anos iniciais ( $1^{\circ}$ e $2^{\circ}$ anos) do Ensino Fundamental que se espera que ela (a criança) se alfabetize". Isso significa que a alfabetização deve ser o foco da ação pedagógica (BRASIL, 2017, p.87).

Esse propósito somente será alcançado quando a dinâmica que envolve o cotidiano de crianças e professores ocupar posição central na elaboração de políticas públicas, pois, "quando isto puder ser efetivado, a questão que se refere à idade de ingresso, seis anos incompletos ou 
completos no início do ano letivo, certamente se tornará um elemento secundário" (GORNI, MAIESKI E MACHADO, 2012, p.20).

Nesse sentido, pode-se afirmar que o ingresso obrigatório da criança no Ensino Fundamental deve primar pelo trabalho pedagógico de qualidade, que supõe planejamento e ações que garantam o atendimento de todas as suas necessidades e contribuam para o seu desenvolvimento intelectual, mas também físico, psíquico e social. Moreno e Paschoal (2009) afirmam:

Defendemos, portanto, uma educação que, em primeira instância, respeite os direitos da criança a um professor qualificado; a um espaço adequado, rico em estímulos, agradável aos olhos infantis; a um tempo bem planejado capaz de satisfazer suas necessidades; à construção de novos saberes; à descoberta do mundo a sua volta; a brincar e ser feliz nesta fase da vida que merece toda a nossa atenção: a infância (MORENO; PASCHOAL, 2009, p. 41).

Considera-se que, não obstante as iniciativas dos órgãos governamentais, bem como os esforços das instituições e de todos os efetivamente envolvidos nesse processo, existe ainda um longo caminho a ser percorrido na conquista da democratização do acesso à educação, especialmente em se tratando de crianças pertencentes às classes sociais menos favorecidas.

\section{A importância das brincadeiras na infância}

A infância é uma etapa importante do desenvolvimento do ser humano que possui singularidades que devem ser não só reconhecidas, mas, sobretudo, respeitadas e promovidas. Dentre as características mais marcantes desse período de vida, pode-se destacar o brincar como sendo de grande importância para a aprendizagem das crianças, desde os primeiros anos de vida.

Assim, o aspecto lúdico constitui uma das mais importantes questões a serem consideradas quando se trata da infância, de sua promoção e do seu direito à formação humana desde o nascimento, visto que os estudos de Leontiev (2001), sobre o desenvolvimento infantil, apontam o brincar como a atividade principal da criança. Para o autor atividade principal consiste na atividade em que correm as mais importantes "mudanças no desenvolvimento psíquico da criança e dentro da qual se desenvolvem processos psíquicos que preparam o caminho da transição da criança para um novo e mais elevado nível de desenvolvimento" (LEONTIEV, 2001, p.122). Desse modo, a atividade principal é aquela que governa, promove e impulsiona o desenvolvimento psíquico da criança em diferentes momentos de sua vida.

Para Mukhina (1995, p.156), quanto mais ampla for a realidade que as crianças conhecem, tanto mais amplos e variados serão os repertórios de seus jogos, pois "o jogo é a atividade 
principal; não porque a criança de hoje passa a maior parte do tempo se divertindo, o que não deixa de ser verdade, mas porque o jogo dá origem a mudanças qualitativas na psique infantil”. Para a autora, a atividade lúdica tem um caráter semiótico ou simbólico, que se expressa por meio do jogo e se reveste de alguns aspectos diferenciados.

O substituto lúdico de um objeto pode ter com esse uma semelhança muito menor do que a que tem um desenho com a realidade que representa. Mas o substituto lúdico oferece a possibilidade de ser manuseado tal como se fosse o objeto que ele substitui. O pré-escolar escolhe objetos substitutos apoiando-se nas relações reais dos objetos (MUKHINA, 1995, p.157).

Diante do exposto, considera-se que a escola tem um importante papel na valorização da infância e na criação de oportunidades para que as crianças se desenvolvam integralmente por meio do brincar. No entanto, para que essa proposta alcance seu objetivo, é necessário o envolvimento e a compreensão por parte dos professores, no sentido de que saibam organizar, definir objetivos e acompanhar atentamente os interesses e as necessidades das crianças em suas brincadeiras.

A esse respeito, Kishimoto (2002, p.37) esclarece que, "quando as situações lúdicas são intencionalmente criadas pelo adulto com vistas a estimular certos tipos de aprendizagem, surge a dimensão educativa". Portanto, para o planejamento e implementação de uma atividade lúdica, o professor necessita: promover a organização da brincadeira, em si, e dos espaços; definir os objetivos; observar atentamente o desenvolvimento da atividade; intervir sempre que necessário; e registrar o desempenho das crianças. Somente desse modo a brincadeira será um meio de potencializar as situações de aprendizagem e a construção de conhecimento, graças às "propriedades do lúdico, do prazer, da capacidade de iniciação e ação ativa e motivadora" (KISHIMOTO, 2002, p.37).

Segundo a Base Nacional Comum Curricular- BNCC (BRASIL, 2017, p. 35), “a interação durante o brincar caracteriza o cotidiano da infância, trazendo consigo muitas aprendizagens e potenciais para o desenvolvimento integral das crianças". Esse documento destaca o brincar como um dos seis direitos de aprendizagem e desenvolvimento, assim orienta que é importante "brincar cotidianamente de diversas formas, em diferentes espaços e tempos, com diferentes parceiros, crianças e adultos” (BRASIL, 2017, p.36).

Em cada momento da vida da criança, o brincar tem funções e significados diferentes, ou seja, para cada faixa etária existe uma forma própria de brincar que permite o melhor desenvolvimento, por isso, é importante que se respeite as possibilidades reais de evolução da criança e sua aprendizagem em cada etapa (PASCHOAL, MELLO, 2007, p.43). 
Para Leontiev (2001, p.135), “as primeiras ações lúdicas surgem com base na necessidade da criança de dominar o mundo dos objetos humanos". Com a evolução da imaginação, nas brincadeiras de faz de conta, surgem as relações humanas, pois, ao brincar com um trem, por exemplo, a criança, além de atuar com o objeto, passa a criar situações imaginárias nas quais precisa estabelecer relações com outras pessoas, tais como os passageiros, o cobrador, o maquinista, entre outros.

Aos poucos, surgem as brincadeiras em grupo, e as crianças brincam não mais uma ao lado da outra, mas juntas (LEONTIEV, 2001). Nessa situação, começam a aparecer algumas regras nas brincadeiras, embora de modo implícito, uma vez que, ao assumir o papel a criança precisa respeitar o conjunto de elementos que, para ela, caracterizam esse personagem. No exemplo da brincadeira de trem, quando uma criança assume o papel de passageiro, precisa subordinar-se a essa condição, ou seja, nas brincadeiras com situações imaginárias e relações sociais acontece "um processo de subordinação da criança às regras da ação, processo este que surge das relações estabelecidas entre os participantes do jogo" (LEONTIEV, 2001, p. 136).

Para Mukhina (1995, p.157), é na atividade lúdica que a criança assume um determinado personagem e atua de acordo com as características do mesmo, já que "está disposta a assumir o papel de uma fera selvagem ou de um cavalo, embora geralmente desempenhe o papel da mãe, do motorista ou do aviador".

As crianças refletem no jogo dramático toda a diversidade da realidade que as circundam: reproduzem cenas da vida familiar e do trabalho, refletem acontecimentos relevantes, como os voos espaciais. A realidade, ao ser representada nos jogos infantis, converte-se em argumentos do jogo dramático (MUKHINA, 1995, p.159).

As brincadeiras em grupo são importantes para o desenvolvimento das interações sociais, pois a criança aprende "a esperar sua vez para ser a mamãe, a princesa ou o motorista do ônibus, a combinar com os amigos a divisão dos papéis, num processo que é negociado com as outras crianças e não imposto pelo adulto" (PASCHOAL, MELLO, 2007, p.45). Dessa forma, a criança cria estratégias de diálogo, conciliação, respeito à opinião do outro, colaboração, argumentação e resolução de problemas, pois "sempre que há discordância em relação às percepções dos papéis sociais, o grupo certamente terá que conversar e se acertar sobre isso" (PASCHOAL, MELLO, 2007, p.45).

Desse modo, as brincadeiras contribuem para o desenvolvimento de habilidades que são fundamentais e atuam como base para a aquisição de conhecimentos posteriores. As brincadeiras e as formas de se relacionar com os brinquedos e objetos vão mudando de acordo com o desenvolvimento da criança, da pré-escola à transição para o primeiro ano do Ensino Fundamental. Por volta dos cinco ou seis anos de idade, surge o interesse pelas primeiras 
atividades com regras, que passam a fazer parte do repertório das crianças e se tornam grandes aliadas no processo de aprendizagem.

Leontiev (2001, p.138) avalia que "a subordinação do comportamento da criança durante o jogo a certas regras reconhecidas de ação, é uma importante precondição para o surgimento da consciência do princípio da própria regra do brinquedo". Para o autor, esse é um aprendizado importante para a criança, uma vez que ela aprende a dominar seu próprio comportamento, ainda que haja estímulos para agir de forma diferente. A criança aprende a se controlar e a se dominar para alcançar um objetivo definido, objetivo este que, em um primeiro momento, é representar fielmente um papel, mas que, em um próximo passo, é cumprir as etapas de um jogo para ser vencedor (LEONTIEV, 2001, p.139).

Os jogos de regras, por terem um objetivo e envolverem dois ou mais participantes, contribuem para que a criança: aprenda a trabalhar em grupo; compreenda e aceite as regras; e desenvolva o autocontrole, a determinação, a capacidade de decisão e a busca por estratégias para atingir o fim almejado. O jogo ensina a criança a lidar com a vitória e o fracasso, com frustrações e com desafios que favorecem o desenvolvimento de atitudes de resiliência. À medida que a criança cresce, as regras vão se tornando mais complexas, e o professor pode inserir conteúdos importantes para o seu aprendizado, por meio de jogos.

Segundo Santos (2001, p. 96), “o período que compreende a larga faixa dos sete aos doze anos será caracterizado por uma fase de transição que culminará com os jogos de regras, próprios da adolescência". A esses jogos de regras simples, que surgem ainda na pré-escola, Leontiev (2001, p.140) denomina de jogos didáticos, pois considera que eles "treinam o desenvolvimento das operações cognitivas necessárias na atividade escolar subsequente da criança, mas não permitem a passagem direta para esse tipo de atividade”. Assim, pode-se considerar que são importantes na transição das atividades pré-escolares para as escolares.

Nessa direção, Kishimoto (2002, p.17) ressalta que as crianças de seis anos continuam sendo crianças, embora estejam no primeiro ano do Ensino Fundamental, assim, sugere que, no currículo dessa etapa, sejam incluídas "brincadeiras que ampliem os interesses das crianças pelas diferentes modalidades de letramento e estendidas cada vez mais a ação orientadora da professora". O aspecto lúdico dos jogos e brincadeiras, torna a aprendizagem mais significativa em todos os níveis de escolarização, desse modo, pode-se considerar que tal experiência é muito importante quando se trata de crianças que iniciam sua vida escolar e podem criar, desde o início, uma relação positiva com a aprendizagem, tornando esse processo muito mais motivador e prazeroso. 
As brincadeiras e os jogos potencializam a aprendizagem e colaboram para a construção do conhecimento, pois atuam a partir de uma motivação interna, no entanto, é fundamental que o professor ofereça também estímulos externos, interação entre crianças e adultos e a sistematização de conceitos em outras situações que não os jogos (KISHIMOTO, 2002).

Nesse contexto, corrobora-se o que afirmam Paschoal e Mello (2007, p. 49) quando apontam que os professores da infância precisam compreender o brincar da criança como elemento fundamental para a formação de funções psíquicas superiores e da "apropriação de valores e sentimentos que constituem as bases para a formação da personalidade madura". Essa conscientização se dará a partir da formação, de debates e do acompanhamento do trabalho de todos os que estão diretamente envolvidos com a educação das crianças, quer sejam professores, coordenadores, pedagogos, gestores e/ou pais.

Reitera-se que a formação, o acompanhamento e a conscientização dos professores são ações fundamentais e imprescindíveis para a promoção e efetivação de uma prática pedagógica que privilegie as brincadeiras, de modo a potencializar, ao máximo, a aprendizagem e o desenvolvimento adequado em cada etapa da educação das crianças. Concomitantemente, ressalta-se que a infância deve ser respeitada, garantida e privilegiada com base em uma proposta centralizada em interações, por meio do brincar, atividade prazerosa e envolvente.

Uma formação sólida, integrada e específica, tão almejada para os professores dos Anos Iniciais do Ensino Fundamental, torna praticável uma educação de excelência. Assim, é por meio dessa formação que deve ser configurado o perfil do educador capaz de conhecer e valorizar as características e as necessidades dos seus alunos, e de, a partir desse conhecimento, potencializar as possibilidades para seu pleno desenvolvimento.

\section{CONSIDERAÇÕES FINAIS}

A infância é uma fase importante na vida do ser humano, portanto, não pode ser suprimida, seja pela privação das manifestações próprias da idade, pela ausência de cuidados ou, ainda, pela antecipação de aprendizagens e responsabilidades. Desse modo, a entrada da criança no ensino fundamental de nove anos, deve ser acolhedora e estimulante no sentido de valorizar as suas manifestações, curiosidades, descobertas, movimentos e, sobretudo, suas brincadeiras. Ao se considerar a importância da infância, foi possível destacar as brincadeiras como uma das principais características dessa fase e como forma elementar de expressão das crianças. Portanto, o aspecto lúdico revelou-se uma das mais importantes questões a serem consideradas na infância, visto que o brincar é a atividade principal da criança. 
Do ponto de vista da aprendizagem, as brincadeiras contribuem para a construção do conhecimento e para a apropriação de valores essenciais para a formação da personalidade da criança. Assim, pode-se considerar que a brincadeira é essencial na prática pedagógica e deve ser incorporada como ferramenta de trabalho do professor. Para tanto, é essencial que os professores recebam uma formação qualificada, pois só assim poderão compreender a importância das brincadeiras como estratégia eficiente para o desenvolvimento das crianças e para a efetivação de uma aprendizagem significativa.

Uma educação de qualidade, só pode se dar por meio do reconhecimento e da valorização da infância e de suas características, ou seja, uma educação humana só se efetiva se tiver como foco a pessoa e o respeito à sua dignidade e aos seus direitos. Por esse motivo a garantia do desenvolvimento profissional e a formação continuada, é condição primordial para a efetivação de uma educação de mais qualidade, pois há uma relação intrínseca entre os processos formativos e a ação docente no contexto escolar.

À luz dos elementos analisados, foi possível constatar que a formação continuada dos professores, atrelada às políticas de valorização profissional é condição primordial para um atendimento de qualidade que respeite os direitos fundamentais da criança e o seu direito de aprendizagem.

\section{REFERÊNCIAS}

ARELARO, Lisete Regina Gomes. O ensino fundamental no Brasil: avanços, perplexidades e tendências. Educ. Soc., Campinas, v. 26, n. 92, p. 1039-1066.

BRASIL. Constituição da República Federativa do Brasil. Brasília, DF: Senado Federal, 1988, 305 p.

BRASIL. Lei no 8.069, de 13 de julho de 1990. Dispõe sobre o Estatuto da Criança e do Adolescente e dá outras providências. Presidência da República, Casa Civil, Subchefia para Assuntos Jurídicos, Brasília, D.F, 13 jul. 1990.

BRASIL. Ministério da Educação. Secretaria de Educação Básica. Departamento de Políticas de Educação Infantil e Ensino Fundamental. Coordenação Geral do Ensino Fundamental. Ensino Fundamental de Nove Anos: Orientações Gerais. Brasília, D.F, jul. 2004.

BRASIL. Lei n ${ }^{\circ} 11.114$ de 16 de maio de 2005. Altera os arts. $6^{\circ}, 30,32$ e 87 da Lei no 9.394 , de 20 de dezembro de 1996, com o objetivo de tornar obrigatório o início do ensino fundamental aos seis anos de idade. Diário Oficial da União: Brasília, D.F, 16 mai. 2005.

BRASIL. Lei n ${ }^{\circ} 11.274$ de 06 de fevereiro de 2006. Altera a redação dos arts. 29, 30, 32 e 87 da Lei $\mathrm{n}^{\circ}$ 9.394, de 20 de dezembro de 1996, que estabelece as diretrizes e bases da educação nacional, dispondo sobre a duração de 9 (nove) anos para o ensino fundamental, com matrícula obrigatória a partir dos 6 (seis) anos de idade. Diário Oficial da União: seção 1, Brasília, D.F, 7 fev. 2006. 
BRASIL. Ministério da Educação. Secretaria de Educação Básica. Secretaria de Educação Continuada, Alfabetização, Diversidade e Inclusão. Conselho Nacional da Educação. Diretrizes Curriculares Nacionais Gerais da Educação Básica. Brasília; MEC, SEB, DCNEB, 2013.

BRASIL. Ministério da Educação. Base Nacional Comum Curricular. BNCC. $3^{a}$ versão. Brasília, D.F, 2017.

BRANDÃO, Carlos da Fonseca. O Ensino Fundamental de Nove Anos e a Legislação Educacional Brasileira. In: BRANDÃO, Carlos da Fonseca; PASCHOAL, Jaqueline Delgado (org.). Ensino Fundamental de Nove Anos: Teoria e Prática na Sala de Aula. São Paulo: Avercamp, 2009. p.17-34.

BREDA, Bruna. O Ensino obrigatório na legislação federal dos séculos XX e XXI. Textura, Canoas, v. 18, n. 36, p.9-21, jan./abr. 2016. Disponível em:

http://www.periodicos.ulbra.br/index.php/txra/article/view/1516/1451. Acesso em: 3 abr. 2021.

FRIGOTTO. Gaudêncio. O enfoque da dialética materialista histórica na pesquisa educacional. In: FAZENDA. Ivani. Metodologia da pesquisa educacional. 3 ed. São Paulo: Cortez, 1994.

GORNI, Doralice Aparecida Paranzini; MAIESKI, Sandra; MACHADO, Vânia Regina Barbosa Flauzino. Ensino fundamental de nove anos: os desdobramentos de uma política

educacional. Rev. de Educação PUC-Campinas, Campinas, v. 17, n. 1, p. 9-22, jan./jun. 2012. Disponível em: https://periodicos.puccampinas.edu.br/seer/index.php/reveducacao/article/view/246/229. Acesso em: 3 abr. 2021. GUILHERME, Claudia Cristina Fiorio. Ensino Fundamental de Nove Anos: da sedução à perversidade. In: ANGOTTI, M. (org.). Educação Infantil: da condição de direito à condição de qualidade no atendimento. Campinas: Elínea, 2009.

KISHIMOTO, Tisuko Morchida (org.). Jogo, brinquedo, brincadeira e a educação. 6. ed. São Paulo: Cortez, 2002.

KRAMER, Sonia. Infância, cultura contemporânea e educação contra a barbárie. Rev. Teias, v. 1, n. 2, p. 1-14, 2000. Disponível em: https://www.e-

publicacoes.uerj.br/index.php/revistateias/article/view/23857. Acesso em: 18 marco. 2021.

KRAMER, Sonia. As crianças de 0 a 6 anos nas políticas educacionais no Brasil: educação infantil e/é fundamental. Educ. Soc., Campinas, v. 27, n. 96, p. 797-818, out. 2006. Disponível em: http://www.scielo.br/pdf/es/v27n96/a09v2796. Acesso em: 21 março. 2021.

LEONTIEV, A. N. Os princípios psicológicos da brincadeira pré-escolar. In: VYGOTSKY, L.S.; LURIA, A.R.; LEONTIEV, A.N. (org.). Linguagem, desenvolvimento e aprendizagem. São Paulo: Ícone, 2001.

MELLO, Suely Amaral. Infância e humanização: algumas considerações na perspectiva históricocultural. Perspectiva, Florianópolis, v. 25, n. 1, p. 83-104, jan,/jun. 2007. Disponível em: ttps://periodicos.ufsc.br/index.php/perspectiva/article/view/1630/1371. Acesso em: 7 abr. 2021. 
MORENO, Gilmara Lupion; PASCHOAL, Jaqueline Delgado. A Criança de Seis Anos no Ensino Fundamental: Considerações Iniciais. In: BRANDÃO, Carlos da Fonseca;

PASCHOAL, Jaqueline Delgado (org.). Ensino Fundamental de Nove Anos: Teoria e Prática na Sala de Aula. São Paulo: Avercamp, 2009. p. 37-50.

MUKHINA, Valéria. Psicologia da idade pré-escolar. São Paulo: Martins Fontes, 1995.

PASCHOAL, Jaqueline Delgado; MELLO, Sueli Amaral. A importância dos jogos e das brincadeiras na infância. In: MORENO Gilmara Lupion; AQUINO, Olga Ribeiro de; PASCHOAL, Jaqueline Delgado. Trabalho pedagógico na educação infantil. Londrina: Humanidades, 2007. p. 41-52.

SANTOS, Vera Lúcia Bertoni dos. Promovendo o desenvolvimento do faz de conta na educação infantil. In: CRAIDY, Carmem Maria; KAERCHER, Gládis Elise Silva. (org.). Educação Infantil pra que te quero? Porto Alegre: Artmed, 2001.

SAVELI, Esméria de Lourdes; Odete Vieira TENREIRO, Maria. Ensino fundamental de nove anos: discurso de diretoras, professoras e coordenadoras pedagógicas. EccoS - Rev. Cient., São Paulo, n. 38, p. 115-128, set./dez. 2011. Disponível em:

https://www.redalyc.org/articulo.oa?id=71545304008. Acesso em: 2 abr. 2021. 